\title{
A REVIEW ON
}

MANET (MOBILE AD HOC NETWORK)

\author{
Suniti Purbey \\ Assistant Professor \\ Amity School of Engineering \& Technology \\ Amity University Chhattisgarh
}

ABSTRACT
MANET or Mobile Ad-hoc Network is a field of networking that deals with the mobiles nodes of communication. These nodes are wirelessly connected with each other. Dynamically interconnections are made. Due to its dynamic behavior, it is necessary to choose apt network type and to handle power consumption issues. In the MANET networks due to mobility and sensing power consumption is the major issue of communication between different nodes. The major Concern of MANET is energy optimization. This paper reviews various types of Mobile Ad-hoc Network and routing protocols and analyses their performance in various application areas along with its advantages and challenges. In addition, we would also explain the various emerging applications and future potential of MANET

KEYWORDS- Nodes, Power consumption, Ad hoc networking, Protocol.

\section{I.INTRODUCTION}

MANET also known as wireless ad hoc network is the keyfactors inthe evolution of wirelesscommunications all over the world. And are even used in military operations, disaster relief andthe conference as well. These networks can change the location and configure itself on the fly.The growth of laptops and 802.11/Wi-Fi wirelessnetworking have made MANET a popular research topic since the1990s. Some important protocols evaluated in MANET are packet drop rate, routing protocol, anend to end packet delays, network throughput.

Through all the existent wireless networks Mobile Ad hoc Network (MANET) have the most essential and unique applications. In comparison to other network architectures, MANET does not require a fixed network infrastructure, as every single node can function as both a transmitter and a receiver. Nodes directly communicate with each other when they are both within theircommunication ranges.[1]

\section{OBJECTIVE}

The objective of this paper is to explain about MANET and other types of Ad hoc networks, Categories, power consumption in MANET, challenges regarding ad hoc networking, routing protocol of Ad hoc networking along with a conclusion and its future applications as well. Even we hadproposed the ways to develop further issues in MANET. 


\begin{tabular}{|c|c|c|c|c|}
\hline $\begin{array}{l}\text { SR, } \\
\text { NO. }\end{array}$ & TITLE OF PAPER & AUTHOR & METHODOLOGY & REMARKS \\
\hline$\underline{1 .}$ & $\begin{array}{l}\text { Mobile ad hoc } \\
\text { networkingImperatives } \\
\text { and } \quad \text { Challenges } \\
\text { ELSEVIER, 2003, 13- } \\
64\end{array}$ & $\begin{array}{l}\text { Imrich Chlamtac } \\
\text { a, Marco Conti } \\
\text { b, Jennifer J.-N. } \\
\text { Liu c, }\end{array}$ & $\begin{array}{l}\text { Introducing the new } \\
\text { technologies such as the } \\
\text { Bluetooth, IEEE } 802.11 \text {, } \\
\text { These recent evolutions } \\
\text { have been generating a } \\
\text { renewed and growing } \\
\text { interest in the research } \\
\text { and development of } \\
\text { MANET. }\end{array}$ & $\begin{array}{l}\text { After introduction } \\
\text { to new } \\
\text { technologies Ad } \\
\text { hoc networking is } \\
\text { being developed } \\
\text { throughout the } \\
\text { time. }\end{array}$ \\
\hline$\underline{2}$. & $\begin{array}{l}\text { "Internet-based } \text { Mobile } \\
\text { Ad Hoc Networking", } \\
\text { IEEE Internet } \\
\text { Computing, pages 63- } \\
\text { 70, July-August 1999. }\end{array}$ & $\begin{array}{l}\text { M.S. Corson,J.P. } \\
\text { Maker }\end{array}$ & $\begin{array}{l}\text { A Mobile Ad hoc } \\
\text { Network (MANET) is a } \\
\text { system of wireless } \\
\text { mobile nodes that } \\
\text { dynamically organize } \\
\text { themselves in arbitrary } \\
\text { and temporary network } \\
\text { topologies. }\end{array}$ & $\begin{array}{lr}\text { In } & \text { MANET, } \\
\text { devices } & \text { totally } \\
\text { works in } & \text { wireless } \\
\text { manner } & \text { using } \\
\text { nodes and } & \text { certain } \\
\text { protocols. }\end{array}$ \\
\hline 3. & $\begin{array}{l}\text { Data Confidentiality in } \\
\text { Mobile Ad hoc } \\
\text { Networks IJARCE } 2010\end{array}$ & $\begin{array}{l}\text { Hamza } \\
\text { Aldabbas, Tariq } \\
\text { Alwada'n, Helge } \\
\text { Janicke, }\end{array}$ & $\begin{array}{l}\text { The self-configuration } \\
\text { and the quick } \\
\text { deployment make ad hoc } \\
\text { networks suitable for } \\
\text { emergency situations } \\
\text { (such as human or } \\
\text { natural disasters) and for } \\
\text { military operations }\end{array}$ & $\begin{array}{l}\text { Here it is discussed } \\
\text { about application } \\
\text { of MANET in } \\
\text { military and } \\
\text { natural disaster }\end{array}$ \\
\hline$\underline{4}$. & $\begin{array}{l}\text { Security in Mobile Ad } \\
\text { Hoc Networks. } \\
\text { Handbook Mobile } \\
\text { Business, 2nd Hershey: } \\
\text { IGI Global, 2009. 541- } \\
\text { 58. }\end{array}$ & $\begin{array}{l}\text { Mehul, Ekata, } \\
\text { and } \\
\text { Limaye }\end{array}$ & $\begin{array}{l}\text { MANETs have the } \\
\text { ability to be set up and } \\
\text { deployed quickly } \\
\text { because it has a simple } \\
\text { infrastructure set-up and } \\
\text { no central administration }\end{array}$ & $\begin{array}{ll}\text { MANETs have } \\
\text { simple } & \\
\text { infrastructure and } \\
\text { don't have any } \\
\text { central } \\
\text { administration. }\end{array}$ \\
\hline$\underline{5}$. & $\begin{array}{l}\text { "Mobile ad hoc } \\
\text { networks Security", 5th } \\
\text { International scientific } \\
\text { Conference on } \\
\text { defensive technologies, } \\
\text { OTECH 2012. }\end{array}$ & $\begin{array}{l}\text { Dragan } \\
\text { MLADENOVIĆ, } \\
\text { Danko } \\
\text { JOVANOVIĆ }\end{array}$ & $\begin{array}{l}\text { Particularly in MANETs } \\
\text { because of regular } \\
\text { variations in topology, } \\
\text { preserving } \\
\text { topological data for } \\
\text { every node includes } \\
\text { more controller overhead } \\
\text { which results in } \\
\text { additional bandwidth } \\
\text { depletion. }\end{array}$ & $\begin{array}{l}\text { Topological data is } \\
\text { preserved in order } \\
\text { to additional } \\
\text { bandwidth } \\
\text { depletion. }\end{array}$ \\
\hline
\end{tabular}

III. LITERATUREREVIEW

Mobile ad hoc networks (MANETs) are complex distributed systems that comprise of wireless mobile nodes that can freely and dynamically organize themselves into arbitrary and 
temporary, 'ad-hoc' network topologies, allowing people and devices to seamlessly internetwork in areas with no pre-existing communication infrastructure, as in case of disaster recovery environments. Ad hoc networking concept is not a new one, having been around in various forms for over 30 Years. Traditionally, tactical networks have been the only communication networking application that followed the ad hoc paradigm. With the introduction of new technologies such as the Bluetooth, IEEE 802.11, eventual commercial MANET deployments have been made outside the military domain. These recent evolutions have been generating a renewed and growing interest in the research and development of MANET [1]. In recent years, the eminent growth of mobile computing devices, which mainly include laptops, personal digital assistants (PDAs) and handheld digital devices, has caused a revolutionary change in the computing world: computing will not merely rely on the capability provided by the personal computers, and the concept of ubiquitous computing emerges and becomes one of the research hotspots in the computer science society [2]. In the ubiquitous computing environment, individual users simultaneously utilize several electronic platforms through which they can access all the required information whenever and wherever they may be [3]. The ubiquitous nature of computing has made it mandatory to adopt wireless network as the interconnection method: it is not possible for the ubiquitous devices to acquire wired network link whenever and wherever they need to connect with other ubiquitous devices. The Mobile Ad Hoc Network is one of the wireless networks that have attracted major thrust from many researchers [4]. A Mobile Ad hoc network (MANET) is a system of wireless mobile nodes that dynamically organize themselves in arbitrary and temporary network topologies. People and vehicles can thus be internetworked in areas without an already communication infrastructure or when the use of such infrastructure requires wireless extension [5]. Perhaps the most widely accepted and acknowledged notion of a mobile ad hoc network is a network formed without any central administration, consisting of mobile nodes that use a wireless interface to send packet data. As the nodes in a network of this kind can serve as routers and hosts, they can forward packets on behalf of other nodes and run user applications [6]. Mobile ad hoc networks are systems that are autonomous, comprised of a number of mobile nodes that communicate through wireless means of communication. They are self-organized, self-configured and self-controlled infrastructure-less networks. These networks have the ability to be set up and deployed quickly because it has a simple infrastructure set-up and no central administration[7]. Mobile ad hoc networks (MANET's) are self-configuring and infrastructure-less networks that are comprised of mobile nodes which communicate over wireless links without any central control and on a peer to peer basis. These individual nodes act as routers to forward both their own data and also their neighbor's data by sending and receiving packets to and from other nodes in the network. The self-configuration and the quick deployment make ad hoc networks suitable for emergency situations (such as human or natural disasters) and for military operations [8]. One scenario is establishing communication between different agents in a disaster recovery operation where e.g. firefighters need to connect to local ambulances and traffic control, in circumstances where the normal communication infrastructure is destroyed or otherwise rendered unusable. In such situations a collection of mobile nodes with wireless network interface can form a transitory network [9]. Mobile ad hoc networks (MANET's) are autonomous systems of mobile nodes connectbywireless links. These nodes are therefore free to move arbitrarily. The topology of these networks changes dynamically and unpredictably. MANETs have many characteristics that make them different from other wireless and wired networks that are widely recognized $[10,11,12,13$, and 14]: 


\section{IV.PROBLEM STATEMENT}

Network partitioning interrupts communication sessions and can be caused by node movement or by node failure due to energy depletion. Whereas the former cannot be controlled by the routing protocol, the latter can be avoided through appropriate routing decisions. Operational lifetime is therefore defined in as the time until network partitioning occurs due to battery out of charge.[16]

- Limited Energy of the nodes

- Difficulties in Replacing the Batteries

- Lack of Central Coordination

\section{V.TYPES OF AD HOC NETWORKS}

There are plenty of Ad hoc networks introduced to us but specifically, we would discuss about some essential and the most commonly used ones such as-

\section{Vehicular ad hoc networks (VANETs)}

The type of Ad hoc network which can be used across vehicles and road safety devices for communication purpose which in turn responsible for smooth and secure vehicle behavior across the roads.

\section{Smartphone-Based Mobile Ad-Hoc Network (SPANs)}

The types of MANET that can be used across mobile phone devices by creating peer-to-peer network through the help of Wi-Fi and Bluetooth.

\section{Internet-Based Mobile Ad-Hoc Networks.}

The type of MANET which works on the concept of networking protocols including User Datagram Protocol, Transmission Control Protocol, Internet Protocol and Routing information protocol.

\section{POWER CONSUMPTION IN MANET}

Power/Energy consumption is one of the most important issues in MANET, basically,Ad hoc networks have nodes those are powered by batteries, which provides limited energy. In absence of basestation,it causes nodes to spend more energy. The nodes can alter theirtransmit power level to maintain the connectivity of the network topology, while gradually increasing the network capacity and reducing the interference and energy consumption. Even the nodes prefer the shortest path in order to conserve energy. On the other hand routing protocol of MANET is one of the major causes of high power consumption, as routing mechanism is totally based on minimum hop count. As the distances between each pair of nodes increases, the amount of power transmitted also increases. If any node dies out of energy in between the process then the whole process would be interrupted and the whole process would be repeated to set new path.[3]

\section{CHALLENGES IN MANET}

Mobile Ad hoc network is used in circumstances where there are no other options to create a network, this feat makes it difficult to establish a network without any existent infrastructure.

1.Restricted wireless transmission range: The radio group will be restricted in the wireless networks and as a result data amounts it can provide much lighter than what a bound network can provide. This involves routing procedures of wireless networks must use the bandwidth in an idealway. This can also be achieved by protecting the overhead as minimum as conceivable. The restricted range enforces restraint on the routingprocess for sustaining the topographical data. Particularly in MANETs because of regular variations in topology, 
preserving the topological data for every node includes more controller overhead which results in additional bandwidth depletion.[15]

2.Packet losses due to transmission errors: Packet loss occurs when one or more packet of data traveling across a computer network fail to reach their destination. Packet loss is either caused by errors in data transmission, typically across wireless networks or network connections. Packet loss is measured as a percentage of packets lost with respect to packets sent.

3.Mobility induced packet losses: location information caused by node mobility produces abad performance of geographic routing protocol as we have shown. Through further analysis, we identify two main problems that account for the performance degradation, namely LLNK and LOOP problems. [14]

\section{APPLICATION OF MANET}

Some distinctive MANET applications include:

Military field: Ad-Hoc networking can permit the army to exploit thebenefit of conventional network expertise for preserving any info network among vehicles, armed forces, and headquarters of information.

Cooperative work: To look after the commercial settings, essential for concerted computing is very significant external to the office atmosphere and surroundings as compared to theinner environment. People want to get outside meetings for exchanging the information plus cooperating with each other regarding any assigned task.

Confined level: Ad-Hoc networks are able to freely associate with immediate in addition, momentary hypermedia network by means of laptop computers for sharing the info with all the contestants' e.g. classroom and conference. Additional valid and confined level application may be in the domestic network where these devices can interconnect straight in exchanging the information.

PAN and Bluetooth: A PAN is local and smallrange network whose devices generally belong to a specified individual. Limited-range MANET like Bluetooth can make simpler the exchange among several portable devices like a laptop, and mobile phones.

Backup Services: liberation processes, accidental recovery, diagnosis or status or data handling in hospitals and replacement of stationary infrastructure.[17]

\section{CONCLUSION AND FUTURE WORK}

In this paper, we went through several research papers related to the topic MANET and discussed its types, power consumption issues, energyoptimization,routing protocols and analyses their performance along with its advantages and challenges, we had also discussed various emerging applications and future potential of MANET. Furthermore, an overview of wireless networks was given, along with a general introduction to MANETs and related routing protocol classifications.

\section{REFERENCE}

[1] Imrich Chlamtac a, Marco Conti b, Jennifer J.-N. Liu c, "Mobile ad hoc networking: Imperatives and Challenges", ELSEVIER, 2003, 13-64

[2] Marco Conti, Body, Personal and Local Ad Hoc Wireless Networks, in Book The Handbook of Ad Hoc Wireless Networks (Chapter 1), CRC Press LLC, 2003.

[3] M. Weiser, "The Computer for the Twenty-First Century", Scientific American, September 1991.

[4] Wenjia Li and Anupam Joshi, Security Issues in Mobile Ad Hoc Networks - A Survey. 
[5] M.S. Corson, J.P. Maker, and J.H. Cirnicione, "Internet-based Mobile Ad Hoc Networking", IEEE Internet Computing, pages 63-70, July-August 1999.

[6] Magnus Frodigh, Per Johansson and Peter Larsson, "Wireless adhoc networking- The art of networking without a network", Ericsson Review No. 4, 2000. 248

[7] Mehul, Ekata, and Vikram Limaye. Security in Mobile Ad Hoc Networks. Handbook Mobile Business, 2nd Ed. Bhuvan Unhelkar. Hershey: IGI Global, 2009. 541-58.

[8] Hamza Aldabbas, Tariq Alwada'n, Helge Janicke, Ali AlBayatti,"Data Confidentiality in Mobile Ad hoc Networks

[9] Subir Kumar Sarkar, T. G. Basavaraju, and C. Puttamadappa. Ad Hoc Mobile Wireless Networks: Principles, Protocols, and Applications. Auerbach Publications, Boston, MA, USA, 2007.

[10] Jameela Al-Jaroodi. Security issues at the network layer in wireless mobile ad hoc Networks at the network layer. Technical report, Faculty of Computer Science and Engineering, University of Nebraska-Lincoln, Nebraska, USA, 2002.

[11] C. Siva Ram Murthy and B.S. Manoj. Ad Hoc Wireless Networks: Architectures and Protocols. Prentice Hall PTR, Upper Saddle River, NJ, USA, 2004.

[12] C.K. Toh. Maximum battery life routing to support ubiquitous mobile computing in Wireless ad hoc networks. IEEE Communications Magazine, 39 (6): 138-147, 2001.

[13] R. Chadha and L. Kant. Policy-driven mobile ad hoc network management. Wiley- IEEE Press, 2007.

[14] D. Djenouri, L. Khelladi, and N. Badache. A survey of security issues in mobile ad hoc Networks. IEEE communications surveys, 7 (4), 2005.

[15] DRAGAN MLADENOVIĆ, DANKO JOVANOVIĆ. "Mobile ad hoc networks Security", 5th International scientific Conference on defensive technologies, OTECH 2012.

[16] Stephen Mueller, Rose P. Tsang, and Dipak Ghosal "Multipath Routing in Mobile Ad Hoc Networks: Issues and Challenges".

[17] Guerin R., Orda A., "QoS-based routing in networks with inaccurate information: Theory and algorithms", in Proc. IEEE INFOCOM'97, Japan, pp. 75-83.

[18] Broch J., Johnson D., Maltz A., "The Dynamic Source Routing Protocol for Mobile Ad Hoc Networks", draft-IETF-manetdsr-03.txt, work in progress. October 1999.

[19] Pravin Ghosekar, Girish Katkar, Dr. Pradip Ghorpade. "Mobile Ad Hoc Networking: Imperatives and Challenges" IJCA Special Issue on "Mobile Ad-hoc Networks" MANETs, 2010. 